\title{
URSOLIC ACID AND CIS-TILIROSIDE PRODUCED BY Merremia tomentosa AFFECT OVIPOSITION OF Leucoptera coffeella ON COFFEE PLANTS
}

\author{
Helvécio M. Santos Júnior ${ }^{\mathrm{a}}$, Karina C. Lopes ${ }^{\mathrm{a}}$, Dejane S. Alves ${ }^{\mathrm{b}, \#}$, Geraldo A. Carvalho ${ }^{\mathrm{b}}$ and Denilson F. Oliveira ${ }^{\mathrm{a}, *}$ \\ aDepartamento de Química, Universidade Federal de Lavras, 37200-000 Lavras - MG, Brasil

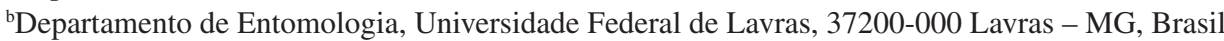

Recebido em 21/09/2017; aceito em 06/12/2017; publicado na web em 18/01/2018

\begin{abstract}
To contribute to the development of new products to control the coffee leaf miner (Leucoptera coffeella), which is a major pest for coffee plants, this work aimed to select plant species able to produce substances active against this insect and to identify the active substances in the selected plant and their protein targets in the insect. Among the extracts of nineteen plant species, only that from leaves of Merremia tomentosa (Choisy) Hall. f. (Convolvulaceae) reduced the oviposition of L. coffeella on leaves of coffee plants. This extract was submitted to successive fractionation steps to achieve the isolation and identification of two active substances, ursolic acid (UA) and cis-tiliroside (CT). An in silico study showed that UA inhibits glycogen phosphorylases (GP) by binding to their allosteric site, while CT probably inhibits xanthine dehydrogenases (XT). As both GP and XT appear to be essential enzymes for insects, these results suggest that, during evolution, L. coffeella learned to identify plants producing inhibitors of these enzymes to avoid oviposition on such plants. Thus, both UA and CT have potential to be used as lead compounds in the development of new products for the control of the coffee leaf miner.
\end{abstract}

Keywords: coffee leaf miner; Coffea arabica; glycogen phosphorylase; xanthine dehydrogenase.

\section{INTRODUCTION}

Coffee is one of the most important crops in Brazil, which is responsible for about $25 \%$ of the global production of this commodity. Thus, great effort has continuously been made to improve the efficiency of the Brazilian coffee production sector, especially by solving phytosanitary problems caused by pests like the coffee leaf miner, Leucoptera coffeella (Guérin-Mèneville, 1842) (Lepidoptera: Lyonetiidae). ${ }^{1}$ Adult females of this insect deposit their eggs on the adaxial leaf surface. After the embryonic stage (4-6 days), larvae hatch out and penetrate into the leaves to feed on their mesophyllic tissues. Subsequently, larvae become chrysalises that adhere to the abaxial leaf surface to be transformed into new moths. Leaves attacked by this insect usually fall off, resulting in plantation defoliation that may result in $68-80 \%$ reduction in coffee production. ${ }^{2}$

Chemical methods are the techniques most often used by coffee producers to control L. coffeella. ${ }^{3}$ The main insecticides employed are organophosphates, pyrethroids and carbamates, which exhibit a wide spectrum of action and are responsible for biological imbalances. ${ }^{4} \mathrm{To}$ circumvent such a problem, plants appear to be promising sources of new products to control insects, since many research groups have demonstrated the ability of several plant species to produce substances active against insects. ${ }^{5}$ Consequently, to contribute to the development of new methods to control the coffee leaf miner, this work initially aimed to select plants able to produce substances that could affect the oviposition of L. coffeella on coffee plants. Then, the most active extract against $L$. coffeella was submitted to successive fractionation steps to achieve the isolation and identification of the major substances of the extract, so that they could be tested against the insect. Finally, an in silico study was carried out to identify the protein targets of the active substances.

*e-mail: denilson@dqi.ufla.br

"Present address: Coordenação do Curso de Ciências Biológicas, Universidade Tecnológica Federal do Paraná, 85892-000 Santa Helena - PR, Brasil

\section{EXPERIMENTAL}

\section{Plant extracts}

Plants used in this study were collected in different regions of Minas Gerais State, Brazil. Species were identified by Prof. Dr. Douglas Antônio de Carvalho at the Department of Biology (Herbário ESAL), Universidade Federal de Lavras, Brazil. They were selected because studies aimed at evaluating their biological activities or identifying their metabolites were scarce. The plant parts were dried at $40{ }^{\circ} \mathrm{C}$ for two days and then crushed into pieces smaller than 2 $\mathrm{mm}$. A portion $(30 \mathrm{~g})$ of each resulting material was submitted to extraction with methanol $(\mathrm{MeOH})$ for $24 \mathrm{~h}$ at room temperature. After filtration through cotton wool plugs, residues underwent three more extractions with $\mathrm{MeOH}$. The liquid phases were combined, concentrated to dryness in a rotary evaporator and freeze-dried to afford the dry extracts (Table 1S).

\section{Adults of L. coffeella}

Adapting a method described in the literature,${ }^{6}$ leaves containing intact mines of the coffee leaf miner, L. coffeella, were obtained from coffee plants (Coffea arabica L. 'Topázio') cultivated in pots containing a mixture of soil, bovine manure and sand (3:2:1, v/v/v), which were kept in a greenhouse. The leaves were fixed to Styrofoam plates by their petioles and placed inside plastic germination boxes, the bottoms of which were covered by cotton wool moistened with water. The boxes were maintained in a climatic chamber with the temperature, relative humidity and photophase per day set at $25 \pm 1{ }^{\circ} \mathrm{C}, 70 \pm 5 \%$ and $14 \mathrm{~h}$, respectively. Every two days, the new pupae were collected and placed in glass tubes, which were kept in the same climatic chamber. Every day, the adults that emerged from pupae were sexed to be used in experiments or to be released in the greenhouse. 


\section{Effects of plant extracts on the oviposition of $L$. coffeella}

Coffee leaves (Coffea arabica L. 'Topázio') without mines of $L$. coffeella were collected in the field, washed with water and cleaned with moistened cotton wool. Then, solutions of the extracts at $8.9 \mathrm{mg} \mathrm{mL}^{-1}$ in aqueous $0.01 \mathrm{~g} \mathrm{~mL}^{-1}$ Tween $80^{\circledR}$ solution were spread on the adaxial leaf surface with a paintbrush. Each leaf was fixed by the petiole to a Styrofoam plate, to which a cleaned leaf with no treatment was already fixed. Each plate was placed in a Petri dish, which was placed in a container formed by a PVC tube $(15 \mathrm{~cm}$ in diameter and $20 \mathrm{~cm}$ long) that was closed with a sheet of paper at each end. Two couples of $L$. coffeella up to three days old were released in each container, which was kept for $72 \mathrm{~h}$ in a climatic chamber with the temperature, relative humidity and photophase per day set at $25 \pm 1{ }^{\circ} \mathrm{C}, 70 \pm 10 \%$ and $14 \mathrm{~h}$, respectively. This experiment was carried out in a completely randomized design, with seven replicates (cages) per treatment. Aqueous $0.01 \mathrm{~g} \mathrm{~mL}^{-1}$ Tween $80^{\circledR}$ and $0.002 \mathrm{~g} \mathrm{~mL}^{-1}$ Lorsban $^{\circledR} 480$ BR [O,O-diethyl-O-(3,5,6-trichloro-2pyridyl) phosphorothioate (also known as chlorpyrifos) at $480 \mathrm{~g} \mathrm{~L}^{-1}$, Dow Agrosciences Industrial Ltda.] were used as controls. Eggs in each cage were then counted and converted into percentages [ $(100 \mathrm{x}$ eggs on treated leaf)/(eggs on treated leaf + eggs on untreated leaf)] before the statistical analysis, which comprised analysis of variance and comparison of means through the Scott and Knott test $(P \leq 0.05)$. Such analysis was carried out with the software SISVAR. ${ }^{7}$

\section{Isolation of substances from the extract of Merremia tomentosa (Choisy) Hall. f. (Convolvulaceae)}

All analyses by thin layer chromatography (TLC) were carried out using aluminum plates covered by a silica gel impregnated with a fluorescent indicator (Alugram, Macherey-Nagel). The spots were visualized using ultraviolet light, iodine vapor, a solution of anisaldehyde in diluted sulfuric acid, or $0.05 \mathrm{~g} \mathrm{~mL}^{-1}$ phosphomolybdic acid in ethanol. A rotary evaporator was used to concentrate all solutions. Fractionation by flash column chromatography (FCC) ${ }^{8}$ was performed by employing silica gel 60 (230-400 mesh, Merck) as the stationary phase.

Initially, the dry extract from leaves of M. tomentosa (20.35 g), obtained as described above, was added to hexane $(200 \mathrm{~mL})$ and the resulting mixture was stirred for $30 \mathrm{~min}$. After filtration through cotton wool plugs, the residue underwent five more extractions with hexane $(5 \times 200 \mathrm{~mL})$. The final residue was subsequently submitted to similar solvent extractions with ethyl acetate (EtOAc; 6 x $200 \mathrm{~mL}$ ) and methanol (MeOH; 6 × $200 \mathrm{~mL}$ ). The liquid phases resulting from extractions with the same solvent were combined, concentrated to dryness and freeze-dried to afford three dry fractions: soluble in hexane (4.34 g), soluble in EtOAc (1.09 g) and soluble in $\mathrm{MeOH}$ (12.01 g). The fraction soluble in EtOAc was analyzed by TLC, and a portion (906 mg) of this fraction was further fractionated by FCC employing a column of silica gel $(3 \times 15 \mathrm{~cm})$ and the following eluents: hexane/ EtOAc (10:1, $200 \mathrm{~mL} ; 3: 1,400 \mathrm{~mL} ; 2: 1,200 \mathrm{~mL} ; 1: 1,200 \mathrm{~mL})$, EtOAc $(200 \mathrm{~mL})$ and $\mathrm{MeOH}(200 \mathrm{~mL})$. After combining the collected fractions ( $18 \mathrm{~mL}$ each) according to their similarities by TLC analysis, they were concentrated and freeze-dried to make 10 subfractions, A1 (fractions 1 to 4), A2 (fractions 5 to 6), A3 (fractions 7 to 12), A4 (fractions 13 to 15), A5 (fractions 16 to 18), A6 (fractions 19 to 23), A7 (fractions 24 to 57), A8 (fractions 58 to 65), A9 (fractions 66 to 68) and A10 (fractions 69 to 78$)$. Subfraction A7 (279 mg) underwent a new fractionation step by FCC using a 3 x $15 \mathrm{~cm}$ column of silica gel. The eluent employed was hexane/EtOAc $(5: 2,1500 \mathrm{~mL})$. After combining the collected fractions ( $19 \mathrm{~mL}$ each) according to their similarities by TLC analysis, they were concentrated and freeze-dried to make 4 new subfractions, A7-1 (fractions 1 to 9), A7-2 (fractions 10 to 13), A7-3 (fractions 14 to 17 ) and to A7-4 (fractions 18 to 78). Subfraction A7-4 $(156 \mathrm{mg})$ underwent TLC analysis and fractionation by FCC using a 3 x $15 \mathrm{~cm}$ column of silica gel and the eluent hexane/EtOAc (1:1, $600 \mathrm{~mL}$ ). Fractions of $20 \mathrm{~mL}$ were collected. This resulted in three new subfractions, A7-4-1 (fractions 1 to 8), A7-4-2 (fractions 9 to 15) and A7-4-3 (fractions 16 to 30). Fraction A7-4-2 (82 mg) was washed four times with hexane/EtOAc $(1: 2,12 \mathrm{~mL})$ and then kept under reduced pressure $(13.33 \mathrm{~Pa})$ for $24 \mathrm{~h}$ to remove any trace of solvent, resulting in a white powder (ursolic acid, 1, $22 \mathrm{mg}$ ) that was a pure compound according to TLC analysis.

A portion $(5.03 \mathrm{~g})$ of the fraction soluble in $\mathrm{MeOH}$ from the crude extract of $M$. tomentosa was subsequently eluted through a $4 \times 10 \mathrm{~cm}$ column of Amberlite XAD-16 resin (Sigma) with water $(200 \mathrm{~mL})$, water/MeOH (80:20, $200 \mathrm{~mL}$; 60:40, $200 \mathrm{~mL}$; 40:60, $200 \mathrm{~mL}$; 20:80, $200 \mathrm{~mL}), \mathrm{MeOH}(200 \mathrm{~mL})$, $\mathrm{MeOH} /$ EtOAc $(50: 50,200 \mathrm{~mL})$ and EtOAc $(200 \mathrm{~mL})$. Eight fractions, corresponding to each eluent employed, were collected and analyzed by high performance liquid chromatography (HPLC) on a Shimadzu CLASS-LC10 apparatus equipped with an ultraviolet-visible diode array detector (DAD) model SPD-10Ai and a Luna silica-C18 analytical column $(5 \mu \mathrm{m}, 250 \times 4.6 \mathrm{~mm}$; Phenomenex). The following eluents were employed: water/MeOH (1:19 to $0: 1$ in $40 \mathrm{~min}$ ) and $\mathrm{MeOH}$ for $5 \mathrm{~min}$. Aliquots of all fractions were also dissolved in hexadeuterated dimethyl sulfoxide $\left(\mathrm{DMSO}-d_{6}\right)$ to obtain hydrogen $\left({ }^{1} \mathrm{H}\right)$ nuclear magnetic resonance (NMR) spectra. Similar fractions according to HPLC and NMR analyses were combined, concentrated and freeze-dried, resulting in two fractions, $\mathrm{M} 1$ (from water to water/MeOH 60:40) and M2 (from water/MeOH 40:60 to EtOAc). A portion of fraction M2 $(650 \mathrm{mg})$ was further fractionated on a preparative HPLC system equipped with an ultraviolet-visible detector set at $254 \mathrm{~nm}$ and a Luna silica-C18 preparative column $(10 \mu \mathrm{m}, 250 \times 21.2 \mathrm{~mm}$, Phenomenex). Acetonitrile (ACN):aqueous $0.5 \%(\mathrm{v} / \mathrm{v})$ acetic acid $(\mathrm{AcOH})(74: 26)$ was used as the eluent. Among the six fractions that were collected (M2-1 to M2-6), M2-5 (trans-tiliroside, 2, $49 \mathrm{mg}$, retention time $22.7 \mathrm{~min}$ ) and M2-6 (cis-tiliroside, 3, $17 \mathrm{mg}$, retention time $25.2 \mathrm{~min}$ ) were pure substances according to analyses by ${ }^{1} \mathrm{H}$ NMR and HPLC-DAD.

\section{Identification of the isolated substances}

To obtain mass spectra, approximately $0.5 \mathrm{mg}$ of each isolated substance (Figure 1) was dissolved in $1.0 \mathrm{~mL}$ water/MeOH (1:9) solution, and $20 \mu \mathrm{L}$ of the resulting solutions were directly infused at a flow rate of $5.0 \mu \mathrm{L} \mathrm{min}{ }^{-1}$ into an Agilent $1100 \mathrm{LC} / \mathrm{MS}$ trap mass spectrometer equipped with an electrospray ionization source in positive and negative ion modes. The probe and cone were maintained at $\pm 3.5 \mathrm{kV}$ and $\pm 25 \mathrm{~V}$, respectively. Nitrogen at 250 and $325^{\circ} \mathrm{C}$ was used as the nebulizer $\left(200 \mathrm{~L} \mathrm{~h}^{-1}\right)$ and gas drier $\left(20 \mathrm{~L} \mathrm{~h}^{-1}\right)$, respectively, while selected ions underwent fragmentation by collisions with helium at 0.6 Pa. Substances were also dissolved in $0.8 \mathrm{~mL}$ of hexadeuterodimethyl sulfoxide (DMSO- $d_{6}$ ), deuterated chloroform $\left(\mathrm{CDCl}_{3}\right)$ or pentadeuterated pyridine (pyridine- $\left.d_{5}\right)$ to obtain uni- and bidimensional NMR spectra of ${ }^{1} \mathrm{H}$ and carbon-13 $\left({ }^{13} \mathrm{C}\right)$, on a Varian Inova 500 spectrometer $\left(500 \mathrm{MHz}\right.$ for ${ }^{1} \mathrm{H}$ and $125 \mathrm{MHz}$ for ${ }^{13} \mathrm{C}$ ). Solvent peaks were used as references.

\section{Effects of the isolated substances on the oviposition of $L$. coffeella}

Each substance (Figure 1) isolated from M. tomentosa was dissolved in $1.0 \mathrm{~mL}$ of an aqueous $0.01 \mathrm{~g} \mathrm{~mL}^{-1}$ Tween $80^{\circledR}$ solution and submitted to the assay with $L$. coffeella as described above. 
Enzymes complexed to ligands similar to ursolic acid or cistiliroside

The structures of ursolate (ursolic acid in the deprotonated state) and cis-tiliroside (Figure 1) underwent conformational searches using the software Open3Dalign 2.103. ${ }^{9}$ One thousand molecular dynamics simulations were carried out for each substance at $1000 \mathrm{~K}$, with a $1 \mathrm{fs}$ time step for $1 \mathrm{ps}$ using the Merck Molecular Force Field 94 (MMFF94), and considering the solvent (water) implicitly using the generalized Born surface area model (GBSA). The most stable conformation of ursolate and the nine most stable conformations of cis-tiliroside were used in pharmacophoric searches employing the software Align-it 1.0.4. ${ }^{10}$ The database used for this search was the Ligand Expo, ${ }^{11}$ which was downloaded from the RCSB Protein Data Bank (http://ligand-expo.rcsb.org) ${ }^{12}$ on July $23^{\text {rd }} 2013$ and converted to sdf format by the software OpenBabel 2.3.0. ${ }^{13}$ Those protein structures complexed to ligands with a Tanimoto score ${ }^{10}$ equal to or above 0.50 were selected for the following steps of this work.

\section{Glycogen phosphorylase}

The PDB and FASTA files for the following glycogen phosphorylases were downloaded from the RCSB Protein Data Bank (http://www.pdb.org): ${ }^{12}$ 1F6D, ${ }^{14}$ 1IOV, ${ }^{15}$ 1L5V, ${ }^{16}$ 1L6I, ${ }^{16}$ 1YGP, ${ }^{17}$ 1Z8D, ${ }^{18}$ 2ATI, ${ }^{19}$ 2C4M (http://www.rcsb.org/pdb/explore/explore. do? structureId=2c4m), 2QLL, ${ }^{20} 2 \mathrm{QN} 1,{ }^{21} 2 \mathrm{QN} 2,{ }^{21} 2 \mathrm{ZB} 2,{ }^{22} 3 \mathrm{CEH},{ }^{23}$ 3DD1, ${ }^{24} 3 \mathrm{SOJ},{ }^{25} 3 \mathrm{SYM},{ }^{26} 3 \mathrm{~T} 3 \mathrm{D},{ }^{27} 4 \mathrm{EJ} 2,{ }^{28} 4 \mathrm{EKE}^{28}$ and $4 \mathrm{EL} 0 .{ }^{28}$ Their amino acid sequences, as well as that of a glycogen phosphorylase from Spodoptera exigua (Hübner, 1808) (Lepidoptera: Noctuidae) (accession number FJ754277.1 in GenBank: http://www.ncbi.nlm.nih.gov/ nuccore/FJ754277), ${ }^{29}$ were aligned using the software Ugene 1.11.5 and the ClustalW 2.1 algorithm ${ }^{31}$ with the default parameters. Then, the amino acid sequences of 1F6D, 1IOV, 1L6I, 1YGP, 1Z8D, 2ATI, 2C4M, 2QLL, 2QN1, 2ZB2, 3CEH, 3DD1, 3SOJ, 4EJ2 and FJ754277.1, were employed in a search for similar amino acid sequences of insects in the nonredundant (nr) database of the NCBI Portal (http://blast.ncbi.nlm. nih.gov/Blast.cgi?CMD=Web\&PAGE_TYPE=BlastHome, accessed on September 5, 2013), using the software BLASTP 2.2.28+ ${ }^{32,33}$ with DELTA-BLAST ${ }^{34}$ set to the default parameters. Only the resulting amino acid sequences with query coverage and identity higher than $90 \%$ and $36 \%$, respectively, were selected for the next step, which comprised alignment of all sequences of amino acids from glycogen phosphorylases, as described above.

\section{Xanthine dehydrogenase}

The PDB and FASTA files for the following xanthine dehydrogenases were downloaded from the RCSB Protein Data Bank (http://www.pdb.org): ${ }^{12} 1 \mathrm{~V} 97,{ }^{35} 3 \mathrm{AMZ},{ }^{36} 3 \mathrm{AX} 7,{ }^{37} 3 \mathrm{NVV},{ }^{38} 3 \mathrm{SR} 6,{ }^{38}$ 3UNA, ${ }^{37} 1 \mathrm{WYG},{ }^{39}$ 2E3T, ${ }^{40}$ 3AN1, ${ }^{36}$ 2CKJ (http://www.rcsb.org/ pdb/explore.do?structureId=2CKJ, accessed on May 19, 2014) and 2E1Q. ${ }^{41}$ Their amino acid sequences were aligned using the software Ugene $1.11 .5^{30}$ and the ClustalW 2.1 algorithm $^{31}$ with the default parameters. Then, the amino acid sequences of 1V97, 1WYG and $2 \mathrm{CKJ}$, were employed in a search for similar amino acid sequences of insects in the nr database of the NCBI Portal (http://blast.ncbi.nlm. nih.gov/Blast.cgi?CMD=Web\&PAGE_TYPE=BlastHome, accessed on April 18, 2014) using the software BLASTP $2.2 .29+{ }^{32,33}$ with DELTA-BLAST ${ }^{34}$ set to the default parameters. Only the resulting amino acid sequences with query coverage and identity higher than $90 \%$ and $36 \%$, respectively, were selected for the next step, which comprised alignment of all sequences of amino acids from xanthine dehydrogenases, as described above.

\section{Docking of substances to glycogen phosphorylases}

Ursolate (deprotonated state of ursolic acid, Figure 1) and all the substances in Figure 2 were used in this step of the work, which was initially carried out by preparing all those substances as described above for ursolate. Then, the Python script Makemultimer.py (http:// watcut.uwaterloo.ca/makemultimer/index) was used to generate PDB files containing the homodimeric glycogen phosphorylases in the complexes 2QN1 and 2QN2 ${ }^{21}$ as well as their ligands, asiatate and maslinate, respectively. The protein structures in these files were aligned in the software Swiss PDB Viewer 4.1.0 (http://www. expasy.org/spdbv), ${ }^{42}$ which automatically added missing atoms to the side chains of amino acid residues. The enzymes as well as all the substances were converted to the PDBQT format using the software Autodock Tools 1.5.6 rc2, ${ }^{43}$ which was also used to select the grid box $(29.25 \times 29.25 \times 29.25 \AA)$ centered over the binding sites of the original ligands (asiatate and maslinate) in the 2QN1 and 2QN2 complexes. Then, all the substances were docked to the enzymes using the software Autodock Vina 1.1.2, ${ }^{44}$ which, except for the exhaustiveness parameter that was set to 128 , used the default values for the other parameters. The PDBQT files of the enzymes and the grid box (grid spacing $=0.375 \AA$ ) were used to calculate atomic affinity potentials for each atom type with the software Autogrid 4.2.3. ${ }^{43}$ The results of this calculation were used by the software Autodock 4.2.3 $3^{43}$ to dock all the substances to the enzymes (an example of the docking parameter file can be found in the supplementary material). Interactions of some ligands with 2QN1 were visually depicted using the software Rasmol 2.7.5, ${ }^{45}$ Pymol (The PyMOL Molecular Graphics System, Version 1.4.1, Schrödinger, LLC) and LigProt+ 1.4.5. ${ }^{46}$

\section{RESULTS AND DISCUSSION}

An oviposition test was chosen to carry out this work because evolutionary theory predicts that the choice of oviposition site is crucial for insect reproductive success, and consequently for its establishment in a crop field. This is particularly important in lepidopterans because their caterpillars have low mobility. Thus, they depend on the choice of feeding site made by adult females. ${ }^{47}$ Furthermore, the use of a product that affects insect oviposition may be advantageous since it can prevent the initial damage caused by the insect to the plant. Thus, an effort to discover natural products affecting the oviposition of insects has been pursued in recent years. ${ }^{5,48}$ Such an approach resulted in the selection of M. tomentosa among several plant species studied as part of a project aiming to identify the biological activities of metabolites produced by native plants in Minas Gerais State, Brazil (Table 1S). Only the extract from leaves of this plant reduced the oviposition of the insect to values statistically equal to those obtained with the commercial insecticide chlorpyrifos, which was used as the positive control in the present work because no product that affects the oviposition of $L$. coffeella without killing the adults has been described in the literature (Table 1).

Although a tea obtained from infusion of M. tomentosa leaves is popularly used as a blood cleanser ${ }^{49}$ no phytochemical study about this plant species has been found in the literature. Furthermore, to the best of the authors' knowledge, no activity of this plant against insects has ever been reported. Consequently, there was no information about the chemical structures of the substances produced by this plant that could affect the oviposition of L. coffeella. Thus, the fractionation of the crude extract of $M$. tomentosa was not directed towards the isolation of any specific group of substances, but targeted the major components of the extract. When this extract underwent solvent extraction, three fractions (soluble in hexane, EtOAc or $\mathrm{MeOH}$ ) were obtained. They accounted for approximately 21.0, 5.3 and $59.0 \%$ 
Table 1. Effects of extract and substances of Merremia tomentosa on the oviposition of Leucoptera coffeella on leaves of coffee plants

\begin{tabular}{lc}
\hline Plant/substance & Oviposition $^{\mathrm{a}}(\%)$ \\
\hline Extract & $6.0 \mathrm{a}$ \\
Cis-tiliroside (3) & $0.0 \mathrm{a}$ \\
Trans-tiliroside (2) & $42.0 \mathrm{~b}$ \\
Ursolic acid (1) & $11.0 \mathrm{a}$ \\
Tween $80^{\circledR}$ (negative control) & $47.2 \mathrm{~b}$ \\
Chlorpyrifos (positive control) & $0.0 \mathrm{a}$ \\
\hline
\end{tabular}

${ }^{a}$ Oviposition $(\%)=[(100 \mathrm{x}$ eggs on treated leaf $) /($ eggs on treated leaf + eggs on untreated leaf)]; values followed by the same letter do not differ according to the Scott and Knott test $(P \leq 0.05)$.

of the plant extract, respectively. The non-polar fraction (soluble in hexane) afforded no purified substance after several steps, but the last sub-fraction in the chromatographic fractionation of the semipolar fraction (soluble in EtOAc) yielded a pure substance after washings with hexane/EtOAc that was identified as ursolic acid (1, Figure 1) based on the NMR data (Table 2S, Figures 1S-11S), which were in agreement with the data published in the literature for the same substance..$^{50,51}$

The production of ursolic acid (1) by M. tomentosa is per se interesting, since this substance presents pharmacological activities, and some assays have demonstrated that it is far less toxic to human beings than the available commercial insecticides to control $L$. coffeella in coffee fields. ${ }^{52}$ Furthermore, it reduced the oviposition of this insect (Table 1), showing potential for use in the development of new products to control this pest. This result seems to be in accordance with the antifeedant activity against Spodoptera litura (Fabricius, 1775) (Lepidoptera: Noctuidae), that was previously described for this substance ${ }^{53}$ and some analogs.$^{54}$ Ursolic acid also showed antifeedant activity against Spilosoma obliqua (Walker, 1855) (Lepidoptera: Arctiidae), ${ }^{53}$ and Achaea janata Linnaeus, 1758 (Lepidoptera: Noctuidae), ${ }^{55}$ and presented growth inhibition and acute toxicity against larvae of Spodoptera frugiperda (J.E. Smith, 1797) (Lepidoptera: Noctuidae), and Drosophila melanogaster (Meigen, 1830) (Diptera: Drosophilidae). ${ }^{56}$

Fractionation of the polar fraction (soluble in $\mathrm{MeOH}$ ) by HPLC, monitored by ${ }^{1} \mathrm{H}$ NMR and HPLC analyses, yielded two isolated substances that were identified as trans-tiliroside (2) and cis-tiliroside (3) through analyses by NMR spectroscopy (Table 3S) and mass spectrometry, during which peaks at $\mathrm{m} / \mathrm{z}$ (mass/charge) $593[\mathrm{M}-\mathrm{H}]$ and $617[\mathrm{M}+\mathrm{Na}]^{+}$were observed for both substances in negative and in positive ion mode, respectively. Their NMR spectra (Figures $12 \mathrm{~S}-31 \mathrm{~S})$ were in agreement with the NMR data in the literature. ${ }^{57}$ Compounds $\mathbf{2}$ and $\mathbf{3}$ were distinguished from one another mainly by the coupling constant between the hydrogen atoms at positions
7"' and 8", which was $16.0 \mathrm{~Hz}$ and $12.5 \mathrm{~Hz}$ for the trans- and cistiliroside respectively.

Cis-tiliroside (3) reduced the oviposition of the insect on leaves of coffee plants, while trans-tiliroside (2) showed no effect on the insect (Table 1). Tiliroside has also been studied due to its potential pharmacological uses, ${ }^{58}$ but to the best of the authors' knowledge, the activity of cis-tiliroside against insects has never been described in the literature. However, kaempferol, one of the aglycones of tiliroside, presents activity against Musca domestica (Linnaeus, 1758) (Diptera: Muscidae), Aedes albopictus (Skuse, 1894) (Diptera: Culicidae), ${ }^{59}$ and Nilaparvata lugens (Stål, 1854) (Hemiptera: Delphacidae). ${ }^{60}$

A pharmacophoric search employing ursolate (deprotonated state of ursolic acid) resulted in the selection of glycogen phosphorylases (Tanimoto score ${ }^{10}=0.68$ ), which catalyze the hydrolysis of glycogen to glucose-1-phosphate and appear to play essential roles in insect energy homeostasis. ${ }^{29,61}$ Unfortunately, no information about the production of these enzymes could be found for L. coffeella. Actually, no three-dimensional structure for glycogen phosphorylases from insects could be found in the literature. When the amino acid sequences of glycogen phosphorylases deposited in the RCSB Protein Data Bank (http://www.pdb.org) ${ }^{12}$ were used to search for similar amino acid sequences of insects through the NCBI portal (http:// blast.ncbi.nlm.nih.gov/Blast.cgi), 43 sequences from Coleoptera, Diptera, Hemiptera, Hymenoptera and Lepidoptera, with coverage and identity to glycogen phosphorylases higher than $90 \%$ and $36 \%$, respectively, were found (Table $4 \mathrm{~S}$ ). Specifically for the enzyme corresponding to the code 2QN1 (100\% identity to the amino acid sequence of 2QN2), the similarities to those produced by insects in the order Lepidoptera were all above $80 \%$ (Table 2), suggesting that the glycogen phosphorylase in complexes 2QN1 and 2QN2 can be used as model to study the corresponding enzymes produced by insects in this order.

According to the literature, inhibition of glycogen phosphorylases like the protein in the 2QN1 (and 2QN2) complex may occur through binding to an allosteric site to which the physiological activator adenosine monophosphate (AMP) binds and which is located about $30 \AA$ away from the catalytic site of the enzyme. Substances like asiatate and maslinate, which are structurally similar to ursolate, as well as (S)-3-(1-methylethyl) 4-(2-chlorophenyl)-1,4-dihydro-1ethyl-2-methylpyridine-3,5,6-tricarboxylate (W1807), 4-[2,4-bis-(3nitrobenzoylamino)phenoxy]phthalic acid (Novo4j) and 1-(2-chloro4-fluorobenzoyl)-3-(5-hydroxy-2-methoxy-phenyl)urea (AVE\#21), ${ }^{21}$ inhibit the enzyme by binding to this allosteric site, which was chosen to carry out the study on the interaction of these compounds with the glycogen phosphorylase in complexes 2QN1 and 2QN2. Other substances structurally similar to ursolate and active against insects according to the literature were also docked to the allosteric site of the enzyme (Figure 2).

As expected, the results obtained with the two docking programs were not equal, but the same tendency can be observed for both of
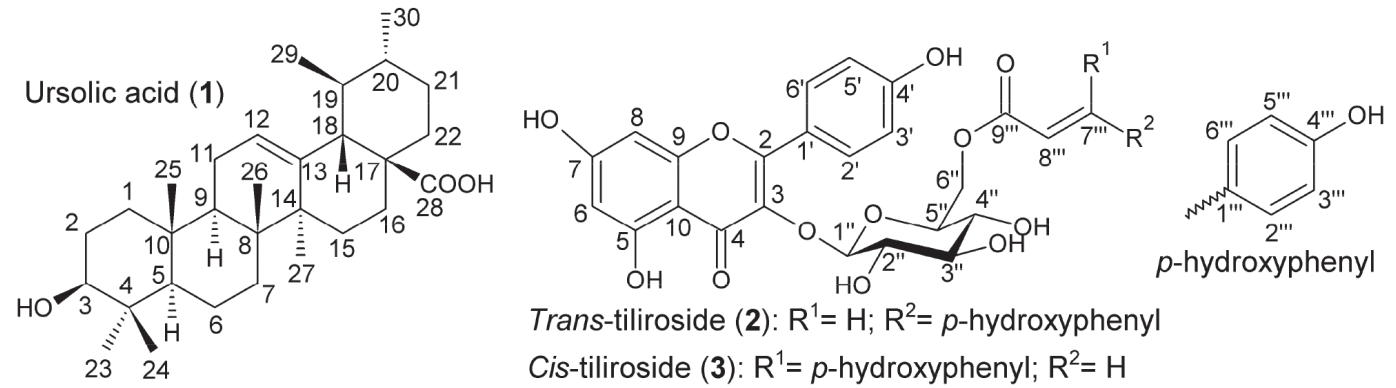

Figure 1. Chemical structures of ursolic acid (1), trans-tiliroside (2) and cis-tiliroside (3), which were isolated from Merremia tomentosa 
Table 2. Amino acid sequence identities of the glycogen phosphorylase in the complex $2 \mathrm{QN} 1^{21}$ to the amino acid sequences transcribed from the genome of insects in the order Lepidoptera

\begin{tabular}{lccc}
\hline Accession number in Genbank & Identity to $2 \mathrm{QN1} 1^{\mathrm{b}}(\%)$ & $\begin{array}{c}\text { Number of amino acid } \\
\text { residues }\end{array}$ & Insect \\
\hline FJ754277.1 & 83 & 841 & Spodoptera exigua (Hübner, 1808) (Lepidoptera: Noctuidae) \\
ACN78408.1 & 83 & 841 & \\
AFO54708.2 & 82 & 841 & Ostrinia furnacalis (Guenée, 1854) (Lepidoptera: Crambidae) \\
EHJ77865.1 & 83 & 840 & Danaus plexippus (Linnaeus, 1758) (Lepidoptera: Nymphalidae) \\
NP_001116811.1 & 83 & 841 & Bombyx mori (Linnaeus, 1758) (Lepidoptera: Bombycidae)
\end{tabular}

${ }^{\mathrm{a}} \mathrm{GenBank}$ (http://blast.ncbi.nlm.nih.gov/). ${ }^{\mathrm{b}}$ Amino acid sequences were aligned using the software Ugene $1.11 .5^{30}$ and the ClustalW 2.1 algorithm. ${ }^{31}$

Autodock Vina 1.1.2

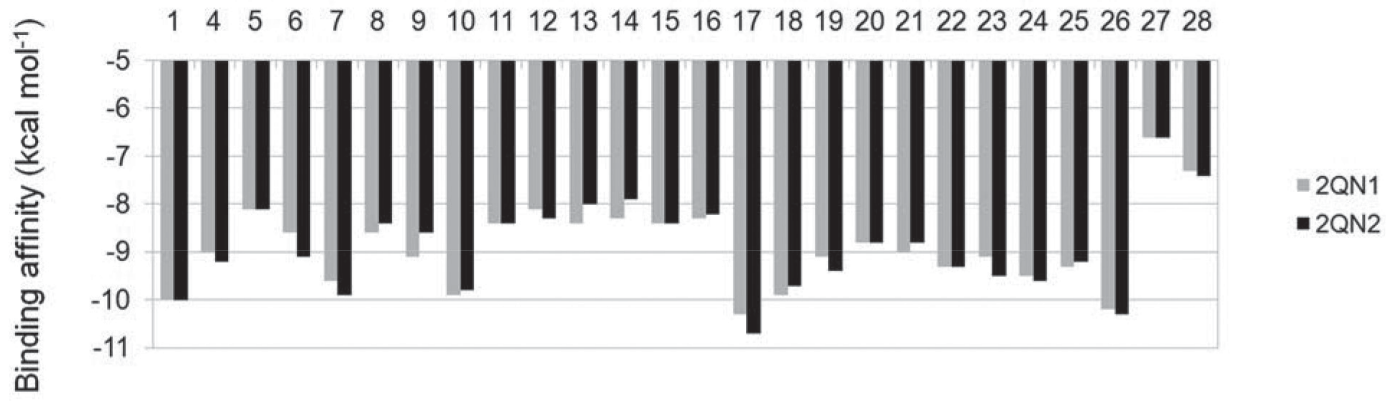

Autodock 4.2 .3

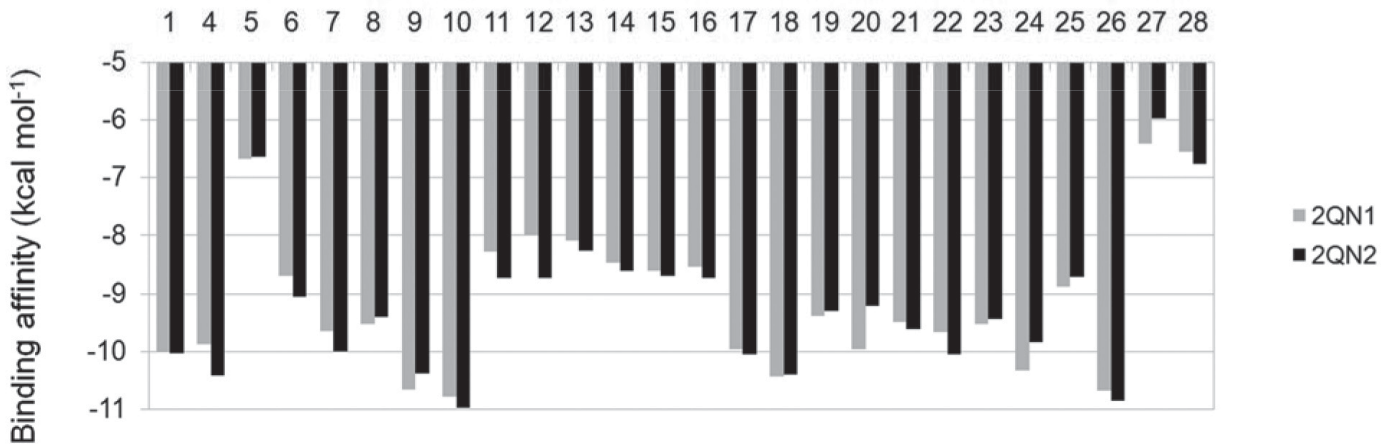

Figure 2. Binding affinities of substances to glycogen phosphorylase in the complexes $2 Q N 1$ and $2 Q N 2,{ }^{21}$ calculated using the software Autodock Vina 1.1.2 ${ }^{44}$ and Autodock 4.2.3. ${ }^{43}$ 1: ursolate; 4: asiatate $;{ }^{62}$ 5: AVE\#21; ${ }^{21}$ 6: aphanalide L; ${ }^{63}$ 7: aphanalide M; ${ }^{63}$ 8: aphanalide I; ${ }^{63}$ 9: $\beta$-sitosterol, $;{ }^{55}$ 10: betulinate; ${ }^{55}$ 11: brianthein $Y ;{ }^{64} 12$ : ptilosarcenone $;{ }^{65} 13$ : ptilosarcone; ${ }^{65} 14$ : ptilosarcen-12-propionate; ${ }^{65} 15$ : litophynin $A ;{ }^{66} 16:$ litophynin C; ${ }^{67} 17: 20$ - $\alpha$-hydroxytingenone; ${ }^{68}$

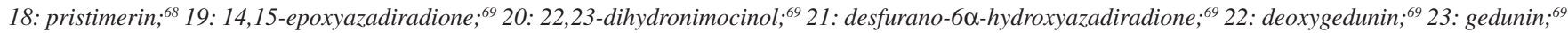
24: maslinate $;^{21}$ 25: Novo4j; $;^{21}$ 26: taraxerol $;{ }^{70} 27:$ AMP $;{ }^{21} 28:$ W180 $7^{21}$

them. For example, maslinate and asiatate presented high affinity values, which seems reasonable because the enzyme in complexes 2QN1 and 2QN2 was crystallized with these substances in their allosteric site, which probably caused the format of the site to become more suitable to those substances. ${ }^{71}$ For example, in the best pose of asiatate docked by the software Autodock Vina 1.1.2 to the allosteric site of the enzyme in complex 2QN1, the ligand can clearly form hydrogen bonds with the amino acid residues Gln72 (chain A), Arg310 (chain A) and Asp42 (chain B), which probably favors the interaction of asiatate with the enzyme (Figure 32S-34S). Conversely, AMP, W1807, Novo4j and AVE\#21, which are structurally different from asiatate and maslinate, afforded lower affinity values than expected for compounds known for their ability to bind to the allosteric binding site of glycogen phosphorylases (Figure 2). Apparently, this result is mainly a consequence of the interaction of polar groups of these substances with non-polar groups in the allosteric site of the enzyme (Figure 35S-46S).

Although a hydrogen bond was formed between the hydroxyl group of ursolate and the amino acid residue Ser317 (chain A), most of the interactions of this substance with the enzyme (Figure 3, 47S-49S) occurred between non-polar groups. Even with a binding site assuming a conformation adapted to asiatate (or maslinate), ursolate (the deprotonated state of ursolic acid) presented affinity values very close to those observed for asiatate and maslinate (Figure 2), suggesting that ursolic acid really is able to inhibit the glycogen phosphorylase produced by L. coffeella.

Among the other substances studied, some of them presented very high affinity values. One example is taraxerol, which is active against 

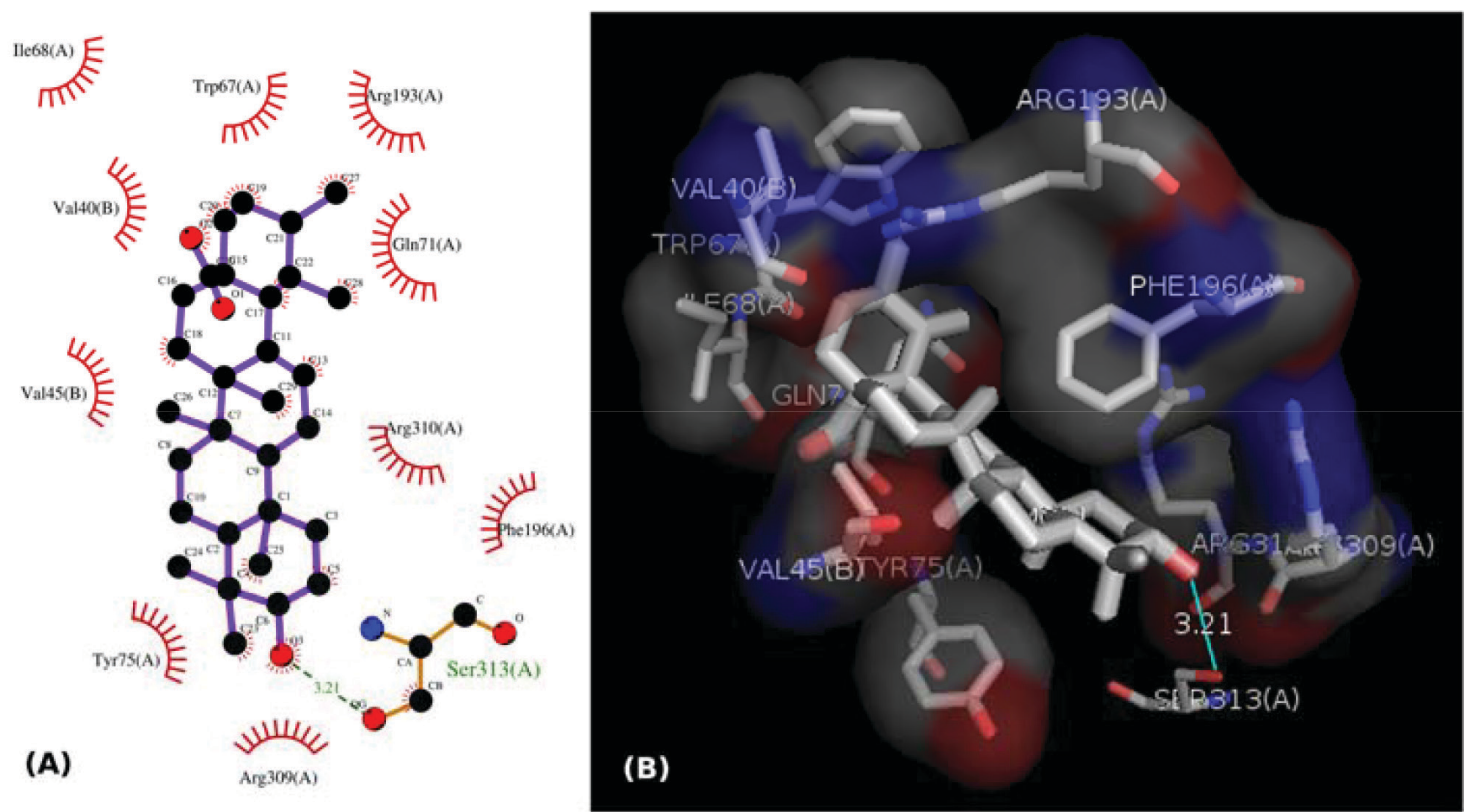

Figure 3. (A) $2 D$ representation of the interaction of ursolate with the enzyme glycogen phosphorilase in complex $2 Q N 1$. (B) $3 D$ representation of the interaction of ursolate with the enzyme glycogen phosphorilase in complex 2QN1. Ursolate was docked to the allosteric site of the enzyme with the software Autodock Vina 1.1.2

Cylas formicarius (Fabricius, 1798) (Coleoptera: Curculionidae).$^{70}$ This substance presented very high affinity for the enzyme according to the calculations carried out with the software Autodock 4.2.3. 20 - $\alpha$-hydroxytingenone, a substance active against $C y$ dia pomonella (Linnaeus, 1758) (Lepidoptera: Tortricidae), ${ }^{68}$ is another example. Betulinate is also worth mentioning because it is active against $A$. janata. ${ }^{55}$ These results suggest that at least part of the mechanism of action of these substances against insects consists of inhibiting their glycogen phosphorylases, which could become important targets for the development of new products to control insects.

In contrast to what was observed for ursolic acid, the pharmacophoric search based on the structure of cis-tiliroside resulted in several enzymes with similar values of the Tanimoto score (Table 5S), but only for xanthine dehydrogenase could a connection with insects be found in the literature. For example, when the gene encoding this enzyme is silenced in Lutzomyia longipalpis (Lutz \& Neiva, 1912) (Diptera: Psychodidae), a reduced life span is observed for the insect. ${ }^{72}$ If an inhibitor of xanthine dehydrogenase like allopurinol is added to the diet used to feed Anticarsia gemmatalis (Hübner, 1818) (Lepidoptera: Noctuidae), and S. frugiperda, increased mortality, slow development and reduced insect biomass are observed for both species. ${ }^{73}$ Furthermore, the use of amino acid sequences of xanthine dehydrogenase from vertebrates to search in the genome of insects revealed 59 sequences from Coleoptera,
Diptera, Hemiptera, Hymenoptera, Lepidoptera and Phthiraptera, with coverage and identity to xanthine dehydrogenase higher than $90 \%$ and $36 \%$, respectively (Table $6 \mathrm{~S}$ ). For insects in the order Lepidoptera, the similarities were all above $63 \%$ (Table 3), suggesting that this enzyme really is produced by insects of this order. Unfortunately, the active site of the enzyme contains a molybdenum atom, which makes the docking calculations difficult because docking software contains no parameters to describe this atom.

\section{CONCLUSION}

In conclusion, the extract of M. tomentosa, as well as ursolic acid (1) and cis-tiliroside (3), which were isolated from this extract, reduced the oviposition of L. coffeella on the leaves of coffee plants. According to the computational studies carried out in the present work, these substances may act against insects by respectively inhibiting their glycogen phosphorylases and xanthine dehydrogenases. Thus, these results suggest that, during evolution, L. coffeella learned to identify plants producing inhibitors of these enzymes to avoid oviposition on such plants, since their larvae could be affected by such inhibitors. Therefore, the isolated substances, glycogen phosphorylase and xanthine dehydrogenase, have potential to be used in the development of environmentally friendly products for the control of L. coffeella in coffee fields.

Table 3. Amino acid sequence identities of the xanthine dehydrogenase in complex $1 \mathrm{~V} 97^{35}$ to the amino acid sequences transcribed from the genome of insects in the order Lepidoptera

\begin{tabular}{lccc}
\hline Accession number in Genbank ${ }^{\mathrm{a}}$ & Identity to $1 \mathrm{~V} 97^{\mathrm{b}}(\%)$ & $\begin{array}{c}\text { Number of amino acid } \\
\text { residues }\end{array}$ & Insect \\
\hline BAA21640.1 & 65 & 1356 & Bombyx mori (Linnaeus, 1758) (Lepidoptera: Bombycidae) \\
NP_001037325.1 & 65 & 1356 & \\
BAB47183.1 & 64 & 1335 & \\
NP_001037333.1 & 64 & 1335 & Danaus plexippus (Linnaeus, 1758) (Lepidoptera: Nymphalidae) \\
EHJ74298.1 & 63 & 1335 & \\
EHJ74297.1 & 63 & 1341 & \\
\hline
\end{tabular}

${ }^{a}$ GenBank (http://blast.ncbi.nlm.nih.gov/). ${ }^{b}$ Amino acid sequences were aligned using the software Ugene $1.11 .5^{30}$ and the ClustalW 2.1 algorithm..$^{31}$ 


\section{SUPPLEMENTARY MATERIAL}

Plants studied in the present work (Table 1S); NMR data (Table 2S) and spectra (Figures 1S-11S) of ursolic acid (1); NMR data (Table 3S) and spectra (Figures 12S-31S) for trans- and cistiliroside ( $\mathbf{2}$ and $\mathbf{3}$, respectively); tables with the similarities between glycogen phosphorylase (Table 4S) and xanthine dehydrogenase (Table 6S) deposited in the RCSB Protein Data Bank (www.pdb. org) and amino acid sequences identified in the genome of insects; a table with protein complexes deposited in the RCSB Protein Data Bank that contain ligands structurally similar to cis-tiliroside (Table $5 \mathrm{~S})$; a sample of the parameter file used to carry out docking with Autodock 4.2.3; and images (2D and 3D representation) of the interaction of ligands docked to the enzyme glycogen phosphorilase (Figures 32S-49S); are available at http://quimicanova.sbq.org.br as a free-access PDF file.

\section{ACKNOWLEDGEMENTS}

The authors are grateful to Fundação de Amparo à Pesquisa do Estado de Minas Gerais (FAPEMIG), Coordenação de Aperfeiçoamento de Pessoal de Nível Superior (CAPES), and Conselho Nacional de Desenvolvimento Científico e Tecnológico (CNPq) for financial support and fellowships. The authors also acknowledge the NMR Facility at Brazilian Biosciences National Laboratory (LNBio), CNPEM, Campinas, Brazil for their support with the use of NMR equipaments.

\section{REFERENCES}

1. Guerreiro-Filho, O.; Braz. J. Plant Physiol. 2006, 18, 109.

2. Barrera, J. F.; Encyclopedia of Entomology; Capinera, J. L., ed.; Springer: Netherlands, 2008, chap. 11.

3. Lasmar, O.; Ferreira, M. C.; Decaro Junior, S. T.; Fouquet, G.; Biosci. J. 2016, 32, 1165; Neto, J. G.; da Cunha, J. P. A. R.; Eng. Agric. 2016, $36,656$.

4. Han, Y.; Mo, R.; Yuan, X.; Zhong, D.; Tang, F.; Ye, C.; Liu, Y.; Chemosphere 2017, 180, 42; Staroň, M.; Sabo, R.; Sobeková, A.; Sabová, L.; Legáth, J.; Lohajová, L.; Javorský, P.; Environ. Sci. Pollut. Res. (2017), doi:10.1007/s11356-017-8966-9.

5. Pavela, R.; Plant Prot. Sci. 2016, 52, 229.

6. Reis Jr., R.; Lima, E. R.; Vilela, E. F.; Barros, R. S.; An. Soc. Entomol. Bras. 2000, 29, 849.

7. Ferreira, D. F.; Cienc. Agrotecnol. 2011, 35, 1039

8. Still, W. C.; Kahn, M.; Mitra, A.; J. Org. Chem. 1978, 43, 2923.

9. Tosco, P.; Balle, T.; Shiri, F.; J. Comput. Aided Mol. Des. 2011, 25, 777.

10. Taminau, J.; Thijs, G.; De Winter, H.; J. Mol. Graphics Modell. 2008, $27,161$.

11. Feng, Z.; Chen, L.; Maddula, H.; Akcan, O.; Oughtred, R.; Berman, H. M.; Westbrook, J.; Bioinformatics 2004, 20, 2153.

12. Berman, H. M.; Westbrook, J.; Feng, Z.; Gilliland, G.; Bhat, T. N.; Weissig, H.; Shindyalov, I. N.; Bourne, P. E.; Nucleic Acids Res. 2000, $28,235$.

13. O'Boyle, N. M.; Banck, M.; James, C. A.; Morley, C.; Vandermeersch, T.; Hutchison, G. R.; J. Cheminf. 2011, 3, 33.

14. Campbell, R. E.; Mosimann, S. C.; Tanner, M. E.; Strynadka, N. C.; Biochemistry 2000, 39, 14993.

15. Fan, C.; Park, I. -S.; Walsh, C. T.; Knox, J. R.; Biochemistry 1997, 36, 2531.

16. Geremia, S.; Campagnolo, M.; Schinzel, R.; Johnson, L. N.; J. Mol. Biol. 2002, 322, 413.

17. Lin, K.; Rath, V. L.; Dai, S. C.; Fletterick, R. J.; Hwang, P. K.; Science 1996, 273, 1539.
18. Lukacs, C. M.; Oikonomakos, N. G.; Crowther, R. L.; Hong, L. -N.; Kammlott, R. U.; Levin, W.; Li, S.; Liu, C. -M.; Lucas-McGady, D.; Pietranico, S.; Reik, L.; Proteins 2006, 63, 1123.

19. Klabunde, T.; Wendt, K. U.; Kadereit, D.; Brachvogel, V.; Burger, H.-J.; Herling, A. W.; Oikonomakos, N. G.; Kosmopoulou, M. N.; Schmoll, D.; Sarubbi, E.; von Roedern, E.; Defossa, E.; J. Med. Chem. 2005, 48, 6178.

20. Pautsch, A.; Stadler, N.; Wissdorf, O.; Langkopf, E.; Moreth, W.; Streicher, R.; J. Biol. Chem. 2008, 283, 8913.

21. Wen, X.; Sun, H.; Liu, J.; Cheng, K.; Zhang, P.; Zhang, L.; Hao, J.; Zhang, L.; Ni, P.; Zographos, S.E.; Leonidas, D. D.; Alexacou, K. -M.; Gimisis, T.; Hayes, J. M.; Oikonomakos, N. G.; J. Med. Chem. 2008, 51,3540

22. Onda, K.; Suzuki, T.; Shiraki, R.; Yonetoku, Y.; Negoro, K.; Momose, K.; Katayama, N.; Orita, M.; Yamaguchi, T.; Ohta, M.; Tsukamoto, S.; Bioorg. Med. Chem. 2008, 16, 5452.

23. Anderka, O.; Loenze, P.; Klabunde, T.; Dreyer, M. K.; Defossa, E.; Wendt, K. U.; Schmoll, D.; Biochemistry 2008, 47, 4683.

24. Thomson, S. A.; Banker, P.; Bickett, D. M.; Boucheron, J. A.; Carter, H. L.; Clancy, D. C.; Cooper, J. P.; Dickerson, S. H.; Garrido, D. M.; Nolte, R. T.; Peat, A. J.; Sheckler, L. R.; Sparks, S. M.; Tavares, F. X.; Wang, L.; Wang, T. Y.; Weiel, J. E.; Bioorg. Med. Chem. Lett. 2009, 19, 1177.

25. Alexacou, K. M.; Zhang, Y. Z.; Praly, J.-P.; Zographos, S. E.; Chrysina, E. D.; Oikonomakos, N. G.; Leonidas, D. D.; Bioorg. Med. Chem. 2011, 19,5125 .

26. Manta, S.; Xipnitou, A.; Kiritsis, C.; Kantsadi, A. L.; Hayes, J. M.; Skamnaki, V. T.; Lamprakis, C.; Kontou, M.; Zoumpoulakis, P.; Zographos, S. E.; Leonidas, D. D.; Komiotis, D.; Chem. Biol. Drug Des. 2012, 79, 663.

27. Kantsadi, A. L.; Hayes, J. M.; Manta, S.; Skamnaki, V. T.; Kiritsis, C.; Psarra, A. M.; Koutsogiannis, Z.; Dimopoulou, A.; Theofanous, S.; Nikoleousakos, N.; Zoumpoulakis, P.; Kontou, M.; Papadopoulos, G.; Zographos, S. E.; Komiotis, D.; Leonidas, D. D.; ChemMedChem 2012, 7, 722 .

28. Kantsadi, A. L.; Manta, S.; Psarra, A. M.; Dimopoulou, A.; Kiritsis, C.; Parmenopoulou, V.; Skamnaki, V. T.; Zoumpoulakis, P.; Zographos, S. E.; Leonidas, D. D.; Komiotis, D.; Eur. J. Med. Chem. 2012, 54, 740.

29. Tang, B.; Xu, Q.; Zou, Q.; Fang, Q.; Wang, S.; Ye, G.; Arch. Insect Biochem. Physiol. 2012, 80, 42.

30. Okonechnikov, K.; Golosova, O.; Fursov, M.; Bioinformatics 2012, 28, 1166.

31. Larkin, M. A.; Blackshields, G.; Brown, N. P.; Chenna, R.; McGettigan, P. A.; McWilliam, H.; Valentin, F.; Wallace, I. M.; Wilm, A.; Lopez, R.; Thompson, J. D.; Gibson, T. J.; Higgins, D. G.; Bioinformatics 2007, 23, 2947.

32. Altschul, S. F.; Madden, T. L.; Schäffer, A. A.; Zhang, J.; Zhang. Z.; Miller, W.; Lipman, D. J.; Nucleic Acids Res. 1997, 25, 3389.

33. Schäffer, A. A.; Aravind, L.; Madden, T. L.; Shavirin, S.; Spouge, J. L.; Wolf, Y. I.; Koonin, E. V.; Altschul, S. F.; Nucleic Acids Res. 2001, 29, 2994.

34. Boratyn, G. M.; Schäffer, A. A.; Agarwala, R.; Altschul, S. F.; Lipman, D. J.; Madden, T. L.; Biol. Direct 2012, 7, 12.

35. Okamoto, K.; Matsumoto, K.; Hille, R.; Eger, B. T.; Pai, E. F.; Nishino, T.; Proc. Natl. Acad. Sci. U. S. A. 2004, 101, 7931.

36. Okamoto, K.; Kawaguchi, Y.; Eger, B. T.; Pai, E. F.; Nishino, T.; J. Am. Chem. Soc. 2010, 132, 17080.

37. Ishikita, H.; Eger, B. T.; Okamoto, K.; Nishino, T.; Pai, E. F.; J. Am. Chem. Soc. 2012, 134, 999.

38. Cao, H.; Hall, J.; Hille, R.; J. Am. Chem. Soc. 2011, 133, 12414

39. Nishino, T.; Okamoto, K.; Kawaguchi, Y.; Hori, H.; Matsumura, T.; Eger, B. T.; Pai, E. F.; J. Biol. Chem. 2005, 280, 24888.

40. Asai, R.; Nishino, T.; Matsumura, T.; Okamoto, K.; Igarashi, K.; Pai, E. F.; Nishino, T.; J. Biochem. 2007, 141, 525. 
41. Yamaguchi, Y.; Matsumura, T.; Ichida, K.; Okamoto, K.; Nishino, T.; $J$. Biochem. 2007, 141, 513.

42. Guex, N.; Peitsch, M. C.; Electrophoresis 1997, 18, 2714.

43. Morris, G. M.; Huey, R.; Lindstrom, W.; Sanner, M. F.; Belew, R. K.; Goodsell, D. S.; Olson, A. J.; J. Comput. Chem. 2009, 30, 2785.

44. Trott, O.; Olson, A. J.; J. Comput. Chem. 2010, 31, 455.

45. Bernstein, H. J.; Trends Biochem. Sci. 2000, 25, 453.

46. Wallace, A. C.; Laskowski, R. A.; Thornton, J. M.; Protein Eng. 1995, 8,127

47. Renwick, J. A. A.; Chew, F. S.; Annu. Rev. Entomol. 1994, 39, 377.

48. Kosar, H.; Srivastava, M; J. Biopestic. 2016, 9, 80; Ribeiro, R. C.; Zanuncio, T. V.; Ramalho, F. S.; da Silva, A. D.; Serrão, J. E; Zanuncio, J. C.; Ind. Crops Prod. 2015, 74, 139.

49. Rodrigues, V. E. G.; de Carvalho, D. A.; Plantas medicinais no domínio dos cerrados, Editora UFLA: Lavras, 2001.

50. Alves, J. S.; de Castro, J. C. M.; Freire, M. O.; da-Cunha, E. V. L.; Barbosa-Filho, J. M.; de Silva, M. S.; Magn. Reson. Chem. 2000, 38 , 201.

51. Seebacher, W.; Simic, N.; Weis, R.; Saf, R.; Kunert, O.; Magn. Reson. Chem. 2003, 41, 636.

52. Liu, J.; J. Ethnopharmacol. 2005, 100, 92.

53. Shukla, Y. N.; Rani, A.; Tripathi, A. K.; Sharma, S.; Phytother. Res. 1996, 10, 359 .

54. Mallavadhani, U. V.; Mahapatra, A.; Raja, S. B.; Manjula, C.; J. Agric. Food Chem. 2003, 51, 1952.

55. Chandramu, C.; Manohar, R. D.; Krupadanam, D. G. L.; Dashavantha, R. V.; Phytother. Res. 2003, 17, 129.

56. Muñoz, E.; Escalona, D.; Salazar, J. R.; Alarcon, J.; Céspedes, C. L.; Ind. Crops Prod. 2013, 45, 283.

57. Budzianowski, J.; Skrzypczak, L.; Phytochemistry, 1995, 38, 997; Tsukamoto, S.; Tomise, K.; Aburatani, M.; Onuki, H.; Hirorta, H.; Ishiharajima, E.; Ohta, T.; J. Nat. Prod. 2004, 67, 1839.
58. Silva, G. C.; Pereira, A. C.; Rezende, B. A.; Silva, J. P. F.; Cruz, J. S.; Souza, M. F. V.; Gomes, R. A.; Teles, Y. C. F.; Cortes, S. F.; Lemos, V. S.; Planta Med. 2013, 79, 1003; Qiao, W.; Zhao, C.; Qin, N.; Zhai, H. Y.; Duan, H. Q.; J. Ethnopharmacol. 2011, 135, 515.

59. Ji-Guang, H.; Huan-Huan, Z.; Hui, M.; Han-Hong, X.; Acta Entomol. Sin. 2012, 55, 1355 .

60. Ding, X.; Ouyang, M.-A.; Liu, X.; Wang, R.-Z.; Journal of Chemistry (2013), ID 645086, doi: 10.1155/2013/645086.

61. Steele, J. E.; Insect Biochem. 1982, 12, 131.

62. Gallo, M. B.; Rocha, W. C.; da Cunha, U. S.; Diogo, F. A.; da Silva F. C.; Vieira, P. C.; Vendramim, J. D.; Fernandes, J. B.; da Silva, M. F.; Batista-Pereira, L. G.; Pest Manage. Sci. 2006, 62, 1072.

63. Zhang, Y.; Wang, J.-S.; Wei, D.-D.; Gu, Y.-C.; Wang, X.-B.; Kong, L.-Y.; J. Nat. Prod. 2013, 76, 1191.

64. Grode, S. H.; James Jr., T. R.; Cardellina, J. H.; Onan, K. D.; J. Org. Chem. 1983, 48, 5203.

65. Hendrickson, R. L.; Cardellina II, J. H.; Tetrahedron 1986, 42, 6565.

66. Ochi, M.; Futatsugi, K.; Kotsuki, H.; Ishii, M.; Shibata, K.; Chem. Lett. 1987, 16, 2207.

67. Ochi, M.; Futatsugi, K.; Kume, Y.; Kotsuki, H.; Asao, K.; Shibata, K.; Chem. Lett. 1988, 17, 1661.

68. Avilla, J.; Teixidò, A.; Velázquez, C.; Alvarenga, N.; Ferro, E.; Canela, R.; J. Agric. Food Chem. 2000, $48,88$.

69. Siddiqui, B. S.; Rasheed, M.; Faizi, S.; Firdous; Ali, S. T.; Tariq, R. M.; Naqvi, S. N.; Helv. Chim. Acta 2003, 86, 3342.

70. Williams, L. A. D.; Naturwissenschaften 1999, 86, 450.

71. Weikl, T. R.; von Deuster, C.; Proteins 2009, 75, 104; Csermely, P.; Palotai, R.; Nussinov, R.; Trends Biochem. Sci. 2010, 35, 539.

72. Sant'Anna, M. R. V.; Alexander, B.; Bates, P. A.; Dillon, R. J.; Insect Biochem. Mol. Biol. 2008, 38, 652.

73. Slansky Jr., F.; J. Chem. Ecol. 1993, 19, 2635. 